OPEN ACCESS

Edited by:

Yu Dong,

Curtin University, Australia

Reviewed by:

Philippe Boisse,

Institut National des Sciences

Appliquées de Lyon (INSA

Lyon), France

Fabrizio Sarasini,

Sapienza University of Rome, Italy

*Correspondence:

Zain Zaidi

s.z.zaidi.29@gmail.com

Specialty section:

This article was submitted to Polymeric and Composite Materials,

a section of the journal

Frontiers in Materials

Received: 09 August 2019 Accepted: 18 October 2019 Published: 07 November 2019

Citation: Zaidi Z, Mawad D and Crosky A (2019) Soil Biodegradation of Unidirectional

Polyhydroxybutyrate-Co-Valerate (PHBV) Biocomposites Toughened

With Polybutylene-Adipate-CoTerephthalate (PBAT) and Epoxidized Natural Rubber (ENR) Front. Mater. 6:275. doi: 10.3389/fmats.2019.00275

\section{Soil Biodegradation of Unidirectional Polyhydroxybutyrate-Co-Valerate (PHBV) Biocomposites Toughened With Polybutylene-Adipate-Co- Terephthalate (PBAT) and Epoxidized Natural Rubber (ENR)}

\author{
Zain Zaidi*, Damia Mawad and Alan Crosky \\ School of Materials Science and Engineering, University of New South Wales, Sydney, NSW, Australia
}

The detrimental impact of discarded plastics on the environment has become of increasing concern and this has led to the development of environmentally friendly "green" polymers. PHBV is one such green polymer that offers biodegradability and renewability, however its mechanical performance is quite limited. This can be improved by reinforcement with natural fibers to form green composites, which offer better mechanical properties while retaining biodegradability. There are, however, few studies examining the biodegradation of toughened PHBV composites. In this work, the biodegradation properties of PHBV/30 vol.\% unidirectional flax composites both untoughened and toughened with PBAT and ENR, were studied. Composites were prepared by compression molding PHBV powder interleaved with unidirectional flax fabric. The toughening agents were cryoground and mixed with the PHBV powder prior to molding. Biodegradation was conducted in a natural outdoor soil environment and biodegradability was evaluated through weight loss analysis, optical microscopy and electron microscopy. The biodegradability of neat PHBV was minimal but was increased markedly by addition of flax fibers. The toughened composites showed a faster degradation rate than untoughened PHBV/flax, with PHBV/ENR/flax composites having the highest rate likely due to a specific strain of bacteria found worldwide in soil that attacks natural rubber. The biodegradation properties of the composites were superior to those of conventional plastics used in applications such as computer and mobile phone casings, which indicates potential suitability of this class of materials for these applications.

Keywords: biodegradation, PHBV, unidirectional, ENR, PBAT, soil

\section{INTRODUCTION}

Disposed plastics have increasingly gained attention of the globe in the past 5 years due to their harmful effects on the environment and this has driven the development of environmentally benign "green" polymers (La Mantia and Morreale, 2011). These polymers biodegrade rather than persist in the environment. Although biodegradability can provide a commercial advantage, 
mechanical performance is still paramount for fulfilling the load carrying requirements in engineering applications and biopolymers are yet to compete with synthetic polymers in this area. The mechanical performance of "green" plastics can, however, be improved through fiber reinforcement. Natural plant fibers are attractive as the reinforcement since they are renewable and biodegradable. Incorporation of these fibers into biopolymers provides a fully "green composite." One application which has become of particular concern in recent years is electronic waste, often referred to as e-waste (Ball, 2003). In the e-waste stream, the casings of items such as mobile phones, computers, and printers are of particular interest since these items have only short lives but are made from materials which degrade only slowly. This is an area that could benefit considerably from the use of green materials.

The naturally occurring bacterial polyester, poly(hydroxybutyrate-co-valerate) (PHBV), is a green polymer with a hydrolysable carbon backbone, which allows it to be degraded by bacteria and enzymes and thus limit landfill saturation (Modi et al., 2016). PHBV has been reinforced by a variety of types of natural fibers previously-abaca (Shibata et al., 2002; Bledzki and Jaszkiewicz, 2010; Adam et al., 2013), hemp (Keller, 2003; Hermida and Mega, 2007; Michel and Billington, 2014), kenaf (Avella et al., 2007; Buzarovska et al., 2007; Persico et al., 2011; Russo et al., 2013), jute (Bledzki and Jaszkiewicz, 2010; Adam et al., 2013), coir (Javadi et al., 2010c), and flax (Bledzki and Jaszkiewicz, 2010; Adam et al., 2013). The majority of the work to date has involved short fibers, particulates and nanofibers, with very little work having been conducted on continuous long natural fibers.

Two major studies have investigated continuous fiber reinforcement of PHBV previously. Luo and Netravali (1999) prepared PHBV [3 mol.\% hydroxyvalerate (HV)]/unidirectional (UD) pineapple leaf fiber composites, containing 0-28 vol.\% fiber, using the film stacking/hot pressing route and reported at least 3-fold increases in tensile modulus and strength at 28 vol.\%. Bourban et al. (1997) prepared PHBV (3 mol.\% HV)/regenerated cellulose fiber composites with 9.9 and 26.5 vol.\% fiber by filament winding and hot pressing. The authors reported at least 10 -fold increases in tensile modulus and strength at 26.5 vol.\%. In comparison, most short-fiber additions to PHBV have resulted in increases in mechanical properties of a maximum of 2 -fold, at volume fractions of $30 \%$. Unfortunately, the large increases due to continuous fibers were accompanied by up to $85 \%$ reductions in elongation to break, indicating a heavily embrittling effect of the fibers.

Composites are normally toughened by a variety of agents to counter the embrittling effect of fiber addition. Polybutylene adipate-co-terephthalate (PBAT) and epoxidized natural rubber (ENR) have been added as toughening agents to PHBV/natural fiber composites in many studies but these have all been shortfiber reinforced composites (Javadi et al., 2010a,b,c; Nagarajan et al., 2013a,b; Zhang et al., 2014a,b). There are no studies where unidirectional fibers and toughening agents have been added simultaneously to PHBV to produce a well-rounded high performing green composite.
Although the mechanical properties can be improved through fiber reinforcement and toughening, it is pertinent that the final product be biodegradable. Biodegradation studies have been conducted on untoughened $\mathrm{PHBV} /$ natural fiber composites but there is little to no literature on the biodegradation properties of toughened PHBV composites. The biodegradability of PHBV has been shown by numerous studies to become enhanced after fiber addition. Batista et al. (2010) examined the biodegradation of their PHBV (9.8 mol.\% HV)/peach palm particle (PPp) composites, in a soil mix containing equal parts of fertile soil (with low clay content), horse manure, and beach sand. The authors reported, from SEM observations, that their neat PHBV showed cavities after 2 months, which became more pronounced after 5 months. They found that addition of $\mathrm{PPp}$ increased the biodegradation rate progressively with increased PPp content, which they attributed to the presence of a gap between the particles and matrix which increased (from $\sim 2.5$ to $\sim 10 \mu \mathrm{m}$ ) with particle content. The gap allowed moisture and microorganisms progressively better access to internal PHBV surfaces. After 5 months, the particles showed significant detachment from the matrix and began showing degradation themselves, as evidenced by the presence of cavities within the particles. Similar observations of fibers enhancing the biodegradation of PHBV have been reported for PHBV/lyocell (Shibata et al., 2004), PHBV/flax (Barkoula et al., 2010), and PHBV/abaca (Shibata et al., 2002).

In this work, PHBV was simultaneously reinforced with unidirectional flax and toughened with PBAT or ENR50. The mechanical, thermal, and morphological properties of the resulting composites have been reported previously in Zaidi and Crosky (2019). This study focuses on the biodegradation properties of those composites and elucidates the effect of PBAT and ENR on the biodegradation of PHBV/flax composites.

\section{EXPERIMENTAL}

\section{Materials}

PHBV (ENMAT ${ }^{\circledR}$ Y1000) was obtained from Tianan Biologic Material Co., China. This commercial grade of PHBV contains 3 mol.\% HV (Srithep et al., 2013) and has a melt flow index (MFI) of $2.5 \mathrm{~g} / 10 \mathrm{~min}$ at $170^{\circ} \mathrm{C}$ (Michel and Billington, 2014) and a density of $1.25 \mathrm{~g} / \mathrm{cm}^{2}$ (Srubar et al., 2012). PBAT (Ecoflex ${ }^{\circledR}$ C1200 F) was obtained from BASF, Germany. This commercial grade of PBAT has an MFI of $3.5 \mathrm{~g} / 10 \mathrm{~min}$ and a density of $1.26 \mathrm{~g} / \mathrm{cm}^{3}$ (Savadekar et al., 2015). Epoxidized natural rubber with $50 \%$ epoxidation (ENR50) was used here and was obtained under the trade name Epoxyrene-50 ${ }^{\circledR}$ from Industrial Organics, Australia. It has a density of $1.02 \mathrm{~g} / \mathrm{cm}^{2}$ (Mohamad et al., 2006). Quasi-unidirectional flax (trade name FlaxPly ${ }^{\circledR}$ UD 180) was obtained from LINEO, Belgium. The fabric was supplied with an epoxy-based sizing that constituted $16 \mathrm{wt} . \%$ of the fabric to improve resin impregnation properties. The fabric consisted of thick longitudinal warp yarns interconnected with thin twisted weft yarns at a spacing of $3 \mathrm{~mm}$ using a 4 over/4 under repeating interlacing pattern. The fabric had an areal weight of 180 grams per square meter. The density of flax is $1.4 \mathrm{~g} / \mathrm{cm}^{3}$ (Vanleeuw et al., 2015). 


\section{Composite Preparation}

Unidirectional composite laminates were fabricated in $200 \times$ $200 \mathrm{~mm}$ steel picture frame molds with fitting lids using a 50ton water cooled hot press built by DSTO Australia. 4 ply laminates $\sim 1.5 \mathrm{~mm}$ thick were fabricated by placing pre-cut plies of unidirectional flax cloth having dimensions of $200 \times 200 \mathrm{~mm}$ in the picture frame mold. The composites were fabricated from matrix material in the powder form, with the powder being carefully spread using a flat $50 \mathrm{~mm}$ wide soft brush to obtain a uniform distribution.

For the toughened composites, the PBAT and ENR50 were first cryoground into powder using a Spex ${ }^{\circledR}$ Freezer Mill and then mixed with the PHBV matrix powder. The precool time was $10 \mathrm{~min}$, with the grinding then being conducted at $10 \mathrm{~Hz}$ for 3 cycles, each consisting of $2 \mathrm{~min}$ grinding followed by $2 \mathrm{~min}$ cool down. Due to the self-healing nature of ENR50 (Rahman et al., 2013), $0.1 \mathrm{~g}$ PHBV powder per gram of ENR50 was added for cryogrinding of ENR50 as the PHBV powder prevented ENR50 powder from coalescing back into a solid mass.

Prior to hot pressing the laminates, the layup was dried (in the mold) in a vacuum oven for $24 \mathrm{~h}$ at $80^{\circ} \mathrm{C}$ to remove moisture. Drying at temperatures of $\sim 80^{\circ} \mathrm{C}$ for at least $24 \mathrm{~h}$, with or without vacuum, is common practice for PHBV and natural fibers (Rossa et al., 2013; Russo et al., 2013; Srithep et al., 2013; Zhang et al., 2014b; Berthet et al., 2015). The mold was then immediately transferred to the preheated hot press and the laminates compression molded at $180^{\circ} \mathrm{C}$ and $3.5 \mathrm{MPa}$ for $12 \mathrm{~min}$. A target fiber volume fraction of 0.30 was selected for the study since similar volume fractions have been used widely in the literature. The volume fraction of ENR or PBAT in the toughened composites was 30 vol.\%.

\section{Biodegradability Test Setup \\ Sample Preparation}

Neat PHBV samples were cut from the molded plates. The $\mathrm{PHBV} /$ flax, PHBV/PBAT/flax, and PHBV/ENR/flax composite samples were cut from the 4 ply laminates.

High-impact polystyrene (HIPS) was used as a control material. Specimens $1 \mathrm{~mm}$ thick were cut from the outer plastic casing of a commercial printer that had reached its end of life.

Square specimens measuring $10 \times 10 \mathrm{~mm}$ were guillotine-cut from the plates and a 1-mm hole was drilled through the center.

\section{Soil Burial}

Based on preliminary trials, a location within Centennial Parklands, Sydney was selected for burial of samples for the test. The underlying soil at Centennial Parklands is known as Botany Sand, which is a well-sorted medium sand containing $<1 \%$ clay. It is subrounded and has high sphericity, a density of $2.65 \mathrm{~g} / \mathrm{cm}^{3}$ and its composition has been reported via $\mathrm{x}$-ray diffraction (XRD) to be quartz dominant, with the clay fraction containing kaolinite and illite (Kelly, 1994).

For each material, a $0.8-\mathrm{mm}$ aluminum wire was threaded through each of the three replicates and arranged in a radial pattern as shown in Figure 1. A 300-mm white plastic cable tie was then attached to the center. Colored cable ties of different colors were then attached to the top of the white cable tie to

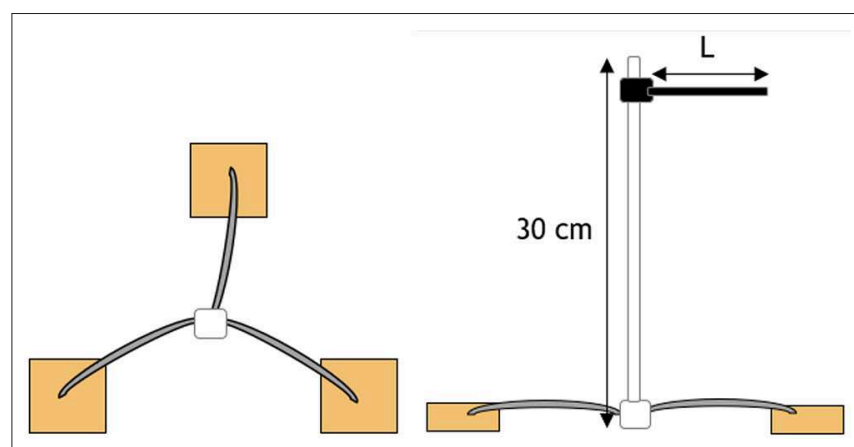

FIGURE 1 | Schematic of radial attachment of a sample triplicate. Triplicates are located $20 \mathrm{~cm}$ below the surface with a color-coded cable tie located $10 \mathrm{~cm}$ above the surface to indicate sample position and identification.

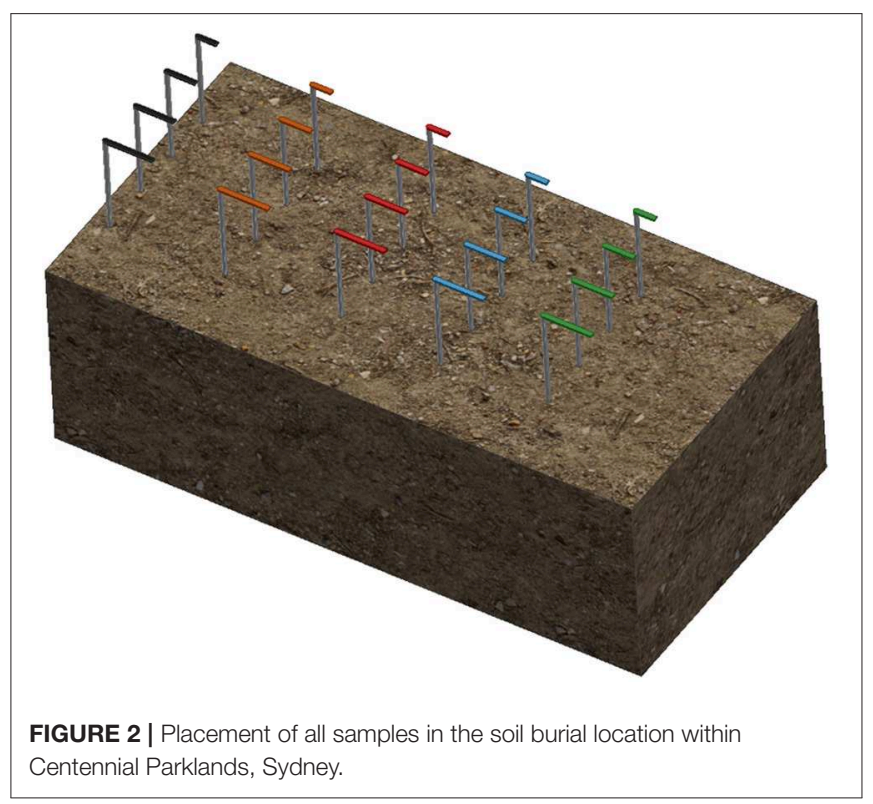

identify the different materials. The colored cable ties were cut to different lengths (L) such that the length corresponded to the duration of the burial period.

A trench measuring $600 \times 300 \times 200 \mathrm{~mm}$ was dug at the selected location and the samples were laid laterally across the trench with a spacing of $50 \mathrm{~mm}$. The soil taken from the trench was used to backfill the trench to the surface. The layout of the samples is shown in Figure 2. The moisture content was governed by natural rainfall.

The soil biodegradation test was conducted on the samples for a maximum burial duration of 112 days, with samples removed for measurement at 28,56,84, and 112 days from burial. The samples were buried from the 28th April 2017 for up to 4 months. Three replicate samples were used for each time period for each of the five materials.

\section{Measurements}

Biodegradation was evaluated through mass loss and surface characterization. 
Daily rainfall data was obtained for the May to August period from the Bureau of Meteorology website, weather station 066062 - Sydney (Observatory Hill). The rainfall data was then superimposed with the mass loss data to examine possible correlations between the rainfall pattern and mass loss.

\section{Mass Loss}

Before burial, samples were dried in an oven at $80^{\circ} \mathrm{C}$ for $24 \mathrm{~h}$ and the initial mass $W_{I}$ was recorded. After retrieval from the burial site, the samples were washed with distilled water, dried at $80^{\circ} \mathrm{C}$ for $24 \mathrm{~h}$, and the final mass $W_{f}$ was recorded. The mass loss, $\Delta W$ was determined according to:

$$
\Delta W(\%)=\left(\frac{W_{I}-W_{f}}{W_{I}}\right) \times 100
$$

\section{Surface Characterization}

After weighing the retrieved samples, their surface features were examined using an ECLIPSE low power optical microscope fitted with a Nikon 600 camera at $5 \mathrm{X}$ magnification.

After examination by optical microscopy, the samples were sputter coated with gold using an EMITECH K550x gold coating unit and examined using a HITACHI S-3400N scanning electron microscope (SEM) operating at $10 \mathrm{kV}$.

\section{RESULTS}

\section{Mass Loss}

The mass loss obtained after each period of time for the neat PHBV, PHBV/flax, PHBV/PBAT/flax, PHBV/ENR/flax, and the HIPS control samples is shown graphically in Figure 3 along with rainfall data.

The HIPS control and neat PHBV samples showed negligible mass losses of 0.4 and $0.5 \%$, respectively, with no appreciable change during the test period.
In contrast the three composites all showed substantial mass losses which increased progressively with time, but at different rates. The highest mass loss was recorded for PHBV/ENR/flax with the lowest being recorded for PHBV/flax. The mass losses after 112 days were $6 \%$ for PHBV flax, 9\% for PHBV/PBAT/flax and $17 \%$ for PHBV/ENR flax.

The rainfall was quite intermittent over the course of the testing. There were several periods of rainfall of $10 \mathrm{~mm}$ or more with a fall of $60 \mathrm{~mm}$ being received over just a few days in one case, Figure 3. However, there appeared to be no distinct correlation between the biodegradation results and the rainfall pattern for the time intervals used in the study.

\section{Surface Characterization Optical Microscopy}

Micrographs of the surface of the HIPS control sample before testing and after the different time intervals are shown in Figure 4. The surface of the sample before testing had a textured appearance associated with its former use as a printer casing. No change in the surface was observed throughout the test period, consistent with the absence of any appreciable mass change.

The surface of neat PHBV samples is shown for the various time intervals in Figure 5. For these samples, color fading was observed with time, as well as coverage of the surface by light colored regions which increased progressively with time and covered most of the surface by 112 days.

Micrographs of the surface of the PHBV/flax samples are shown in Figure 6. Color fading was again observed with time and was more pronounced than in the neat PHBV. With the color fading, the flax fibers became more visible under the surface after 28 days (red arrows), and microcracks began to appear after 56 days (red arrows). Small purple areas of discoloration were also observed at the longest time (red arrows).

Figure 7 shows micrographs of the surface of the PHBV/PBAT/flax samples for the various time intervals.

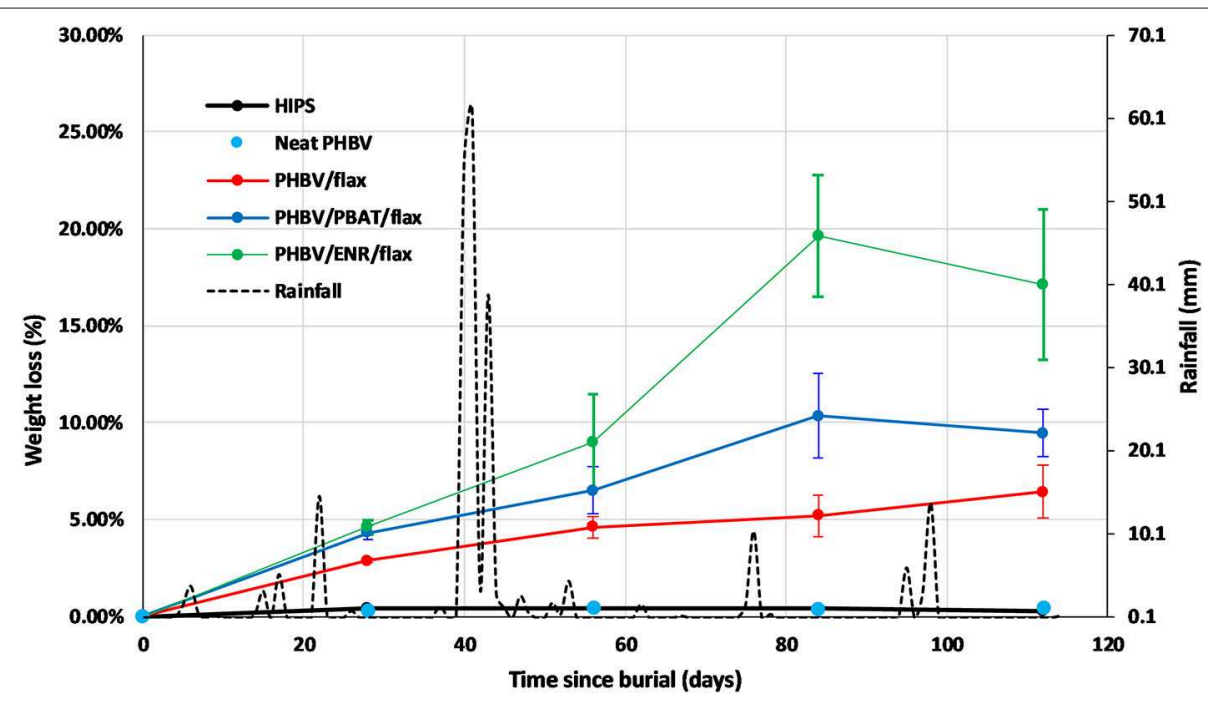

FIGURE 3 | Mass loss curves of HIPS control, neat PHBV, PHBV/flax, PHBV/PBAT/flax, PHBV/ENR/flax, and rainfall data for May to August 2017 period. Error bars represent standard deviation for $n=3$ samples. 


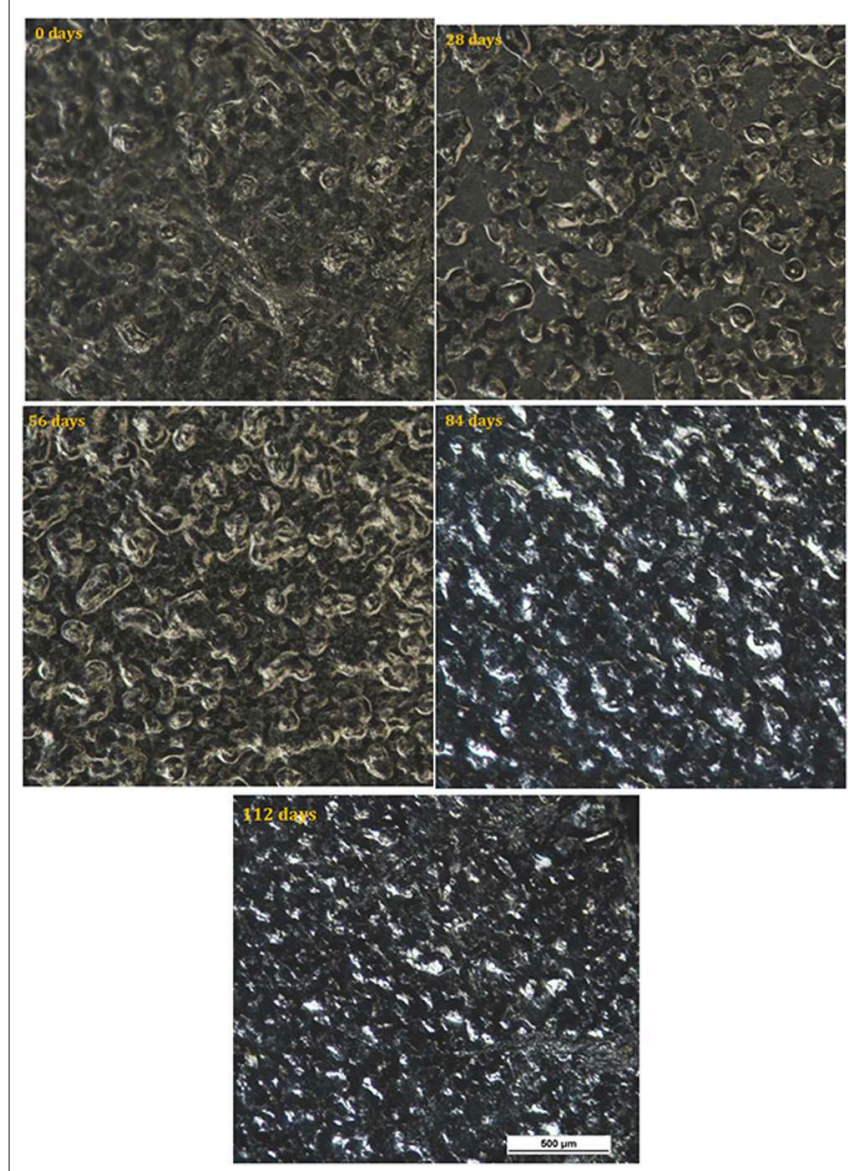

FIGURE 4 | Optical micrographs of HIPS at 0, 28, 84, and 112 days.

Progressive fading and discoloration occurred with increasing burial time. Microcracks and purplish regions were again observed.

Micrographs of the PHBV/ENR/flax samples for the various time intervals are shown in Figure 8. Progressive fading and discoloration were again observed, but this was less pronounced than for PHBV/flax and PHBV/PBAT/flax samples. Microcracks were again observed and purplish and yellow regions were observed at the longer times.

\section{SEM}

\section{Initial surfaces}

The initial surfaces are shown for all samples in Figure 9. All samples showed smooth, featureless surfaces before soil burial, except for the HIPS sample which, as mentioned earlier, showed a degree of roughness.

\section{After 28 days}

The five different materials are shown after 28 days burial in Figure 10. The HIPS sample showed no detectable change as a result of burial. The neat PHBV sample showed faint craze-like markings and some coarse pits. The PHBV/flax, $\mathrm{PHBV} / \mathrm{PBAT} / \mathrm{flax}$, and PHBV/ENR/flax composite samples all began to exhibit microcracks $\sim 50 \mu \mathrm{m}$ wide, together with some

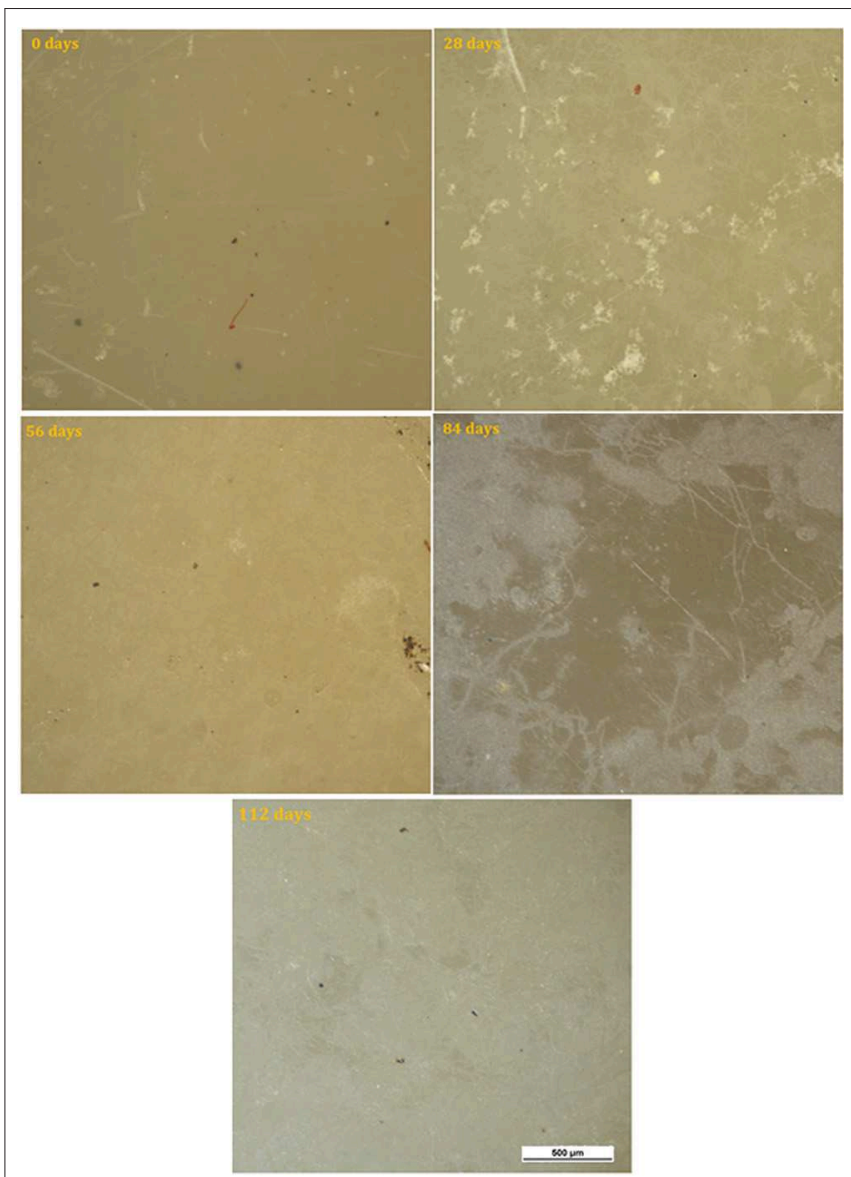

FIGURE 5 | Optical micrographs of neat PHBV at 0, 28, 84, and 112 days.

coarse pits. Light colored patches were also evident across the surface but were more prevalent in the PHBV/PBAT/flax and $\mathrm{PHBV} / \mathrm{ENR} /$ flax samples than in the $\mathrm{PHBV} /$ flax composite.

A region in one of the composites where fibers have become exposed at the surface is shown in Figure 11. The elementary fibers have begun to separate from the fiber bundles while filaments $<1 \mu \mathrm{m}$ in diameter have developed from the fibers.

\section{After 56 days}

The five different materials are shown after 56 days burial in Figure 12. No change was again observed for the HIPS samples. For the neat PHBV samples, the craze markings seen after 28 days burial had become wider and more pronounced, while the surface had begun to become patchy and rougher. The PHBV/flax, PHBV/PBAT/flax, and PHBV/ENR/flax composite samples all showed an increasing level of cracking with the cracks being wider, frequently revealing the flax fibers beneath the surface. The filamentous structures on the flax fibers seen after 28 days in the $\mathrm{PHBV} /$ flax, $\mathrm{PHBV} / \mathrm{PBAT} / \mathrm{flax}$, and PHBV/ENR/flax samples had also become larger and elementary fiber separation was more pronounced. Filamentous structures had begun to develop on 


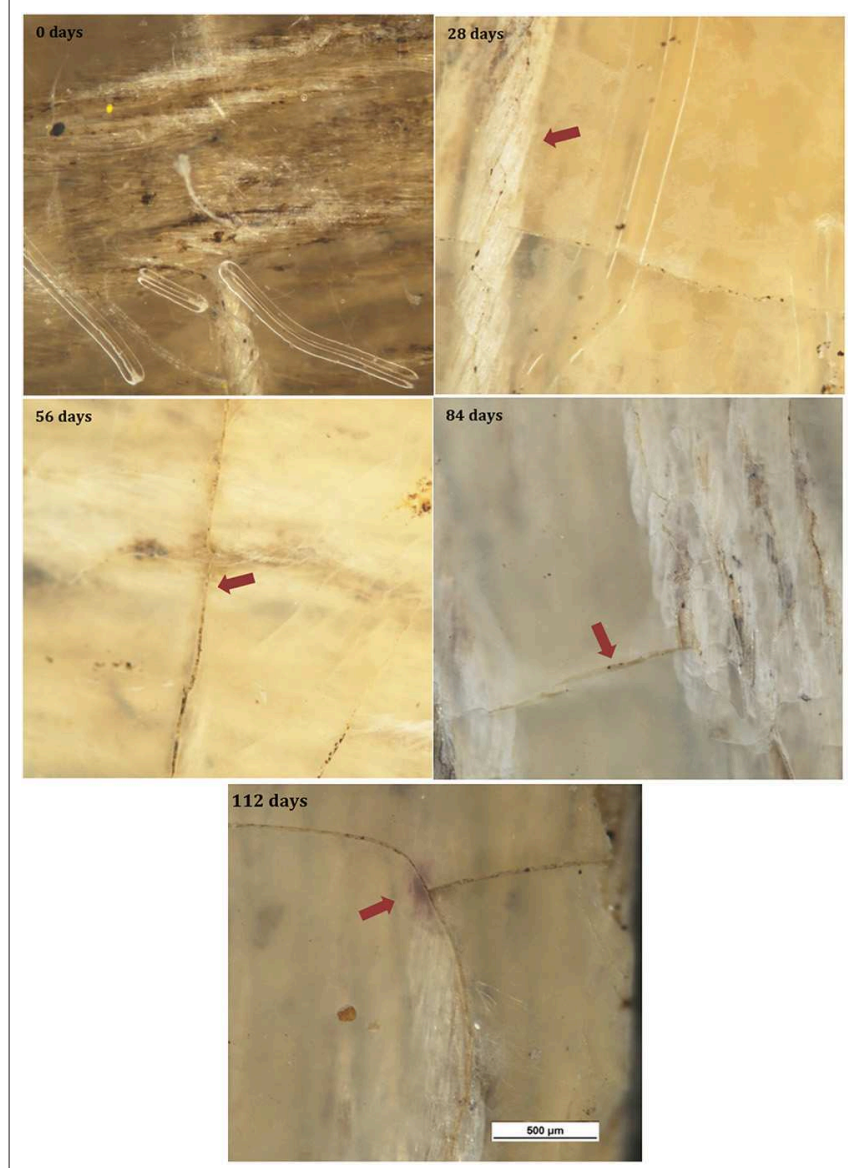

FIGURE 6 | Optical micrographs of PHBV/flax at 0, 28, 84, and 112 days.

the surface of the PHBV/ENR/flax composite and these appeared to be associated with ENR particles. Peanut shaped features $\sim 5 \mu \mathrm{m}$ long had also begun to appear on the PHBV/ENR/ flax sample.

\section{After 84 days}

The five different materials are shown after 84 days burial in Figure 13. The HIPS sample remained unchanged. Neat PHBV became more pitted with pits being much deeper. Cracking in composite samples continued to grow and reveal fibers underneath the surface. The filamentous structures became more extensive on PHBV/PBAT/flax and PHBV/ENR/flax. Some filaments began growing out of the surface, having a hollow and cylindrical appearance.

\section{After 112 days}

Changes in the samples after 112 days burial are shown in Figure 14. The HIPS control sample remained essentially unchanged. For all other samples, the pitting had become essentially continuous across the surface but otherwise there was minimal further change.

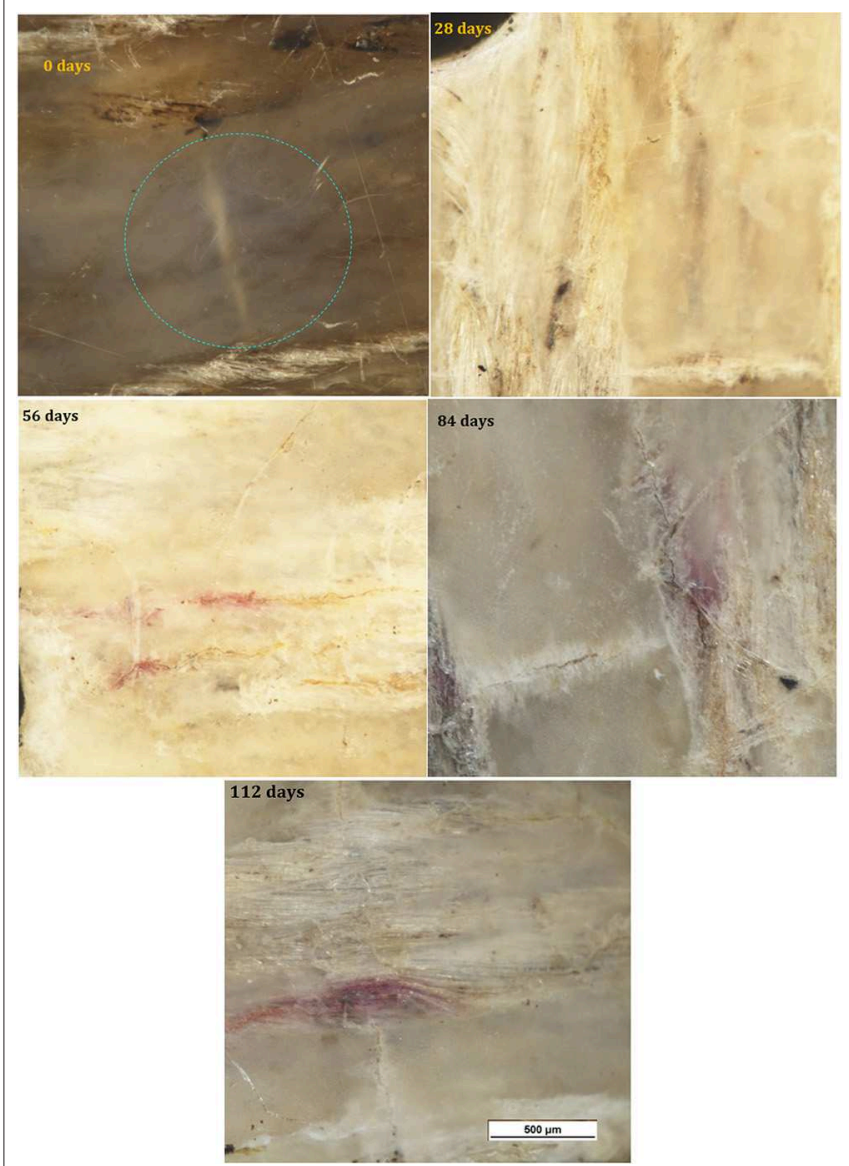

FIGURE 7 | Optical micrographs of PHBV/PBAT/flax at 0, 28, 84, and 112 days.

\section{DISCUSSION}

\section{Mass Loss}

The control HIPS sample underwent negligible loss in mass during burial, as is expected for a non-biodegradable polymer (Ebadi-Dehaghani et al., 2016). A negligible degradation rate ( $0.47 \%$ in 112 days) was also observed for neat PHBV. This is contrary to the reported degradation rates for PHBV, given in Table 1, which are more substantial. However, the data given in Table 1 is for PHBV grades with higher HV contents (5-13\%) than the grade used in the present study $(3 \% \mathrm{HV})$ and this may be responsible for the difference. Differences in soil may also have had an effect.

It is noted that the PHBV samples were buried in close proximity to the composite samples raising the possibility of interference from the latter. However, similarly low rates of degradation were obtained for the neat PHBV samples in preliminary trials in which the PHBV samples were tested separately from the composites. It is concluded therefore that any interference from the composites on the degradation rate of neat PHBV would have been minimal. 


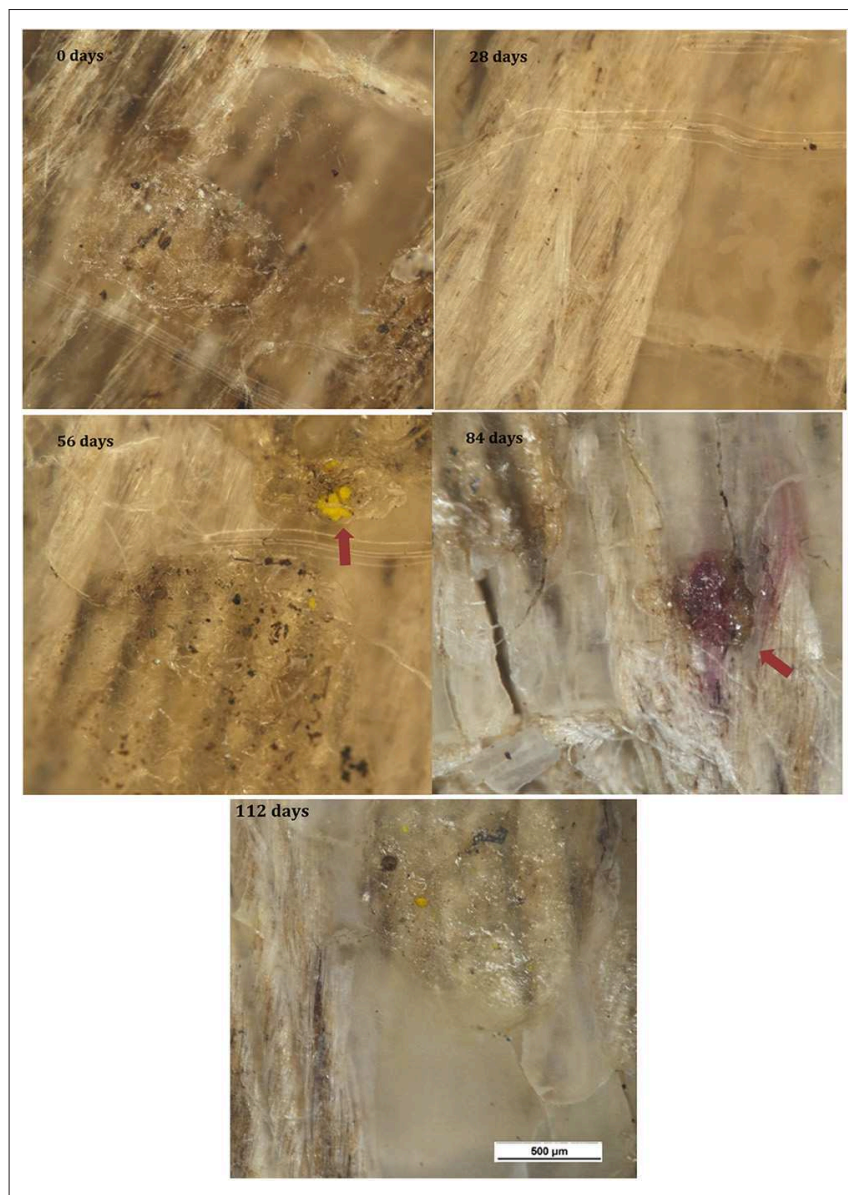

FIGURE 8 | Optical micrographs of PHBV/ENR/flax at 0, 28, 84, and 112 days.

While the mass loss was negligible for the PHBV samples, the SEM micrographs did show evidence of some biodegradation at the exposed surface.

Unlike the neat PHBV, the composites showed substantial degradation rates, with the mass losses after 112 days being $7-17 \%$. The increased mass loss due to natural fiber addition is a common observation in the literature, as flax fibers are highly biodegradable. Alimuzzaman et al. (2014) reported a mass loss of $90 \%$ for flax after 60 days of burial in compost, attributed to all the components of flax-cellulose, lignin, and pectin-being biodegradable. The authors had also reinforced polylactic acid (PLA) with flax and reported that flax addition increased the biodegradability of PLA, as the water-absorbent nature of flax allowed water and microorganisms to be absorbed into the interior of the sample through the cut edges of the composite. Batista et al. (2010) have also reported higher rates of biodegradation in $\mathrm{PHBV} /$ peach palm particle composites than in neat PHBV. Their findings were based on visual and SEM examination since excessive disintegration of the composite samples precluded accurate mass loss measurement. They attributed the higher rate of degradation in the composites to gaps between the fiber particles and the matrix providing channels for microorganisms to reach the inner bulk of the composite, thus allowing degradation from the interior as well as from the surface.

The composites examined by Batista et al. (2010) would be expected to have fibers exposed at the surface but fibers were generally not exposed on the molded surfaces of the composites examined in the present study. However, fibers would be exposed at the cut edges of the samples and ingress of microorganisms might have been possible along the fiber matrix interfaces and through the lumens. The microcracks which developed in the composites during soil burial would also have facilitated microorganism ingress.

The degradation rate was faster in both the toughened composites than in the untoughened composite, with the mass loss after 112 days being 50\% higher for PHBV/PBAT/flax and more than double for the PHBV/ENR/flax. Kumagai and Doi (1992) observed that blends of PHB degraded faster than the pure polymer, which was attributed to phase separation during the blending process. This suggests that the interfaces between the toughening agents and the PHBV matrix may have provided paths for microorganism ingress.

The higher rate of degradation observed for the ENR toughened composite than its PBAT toughened counterpart is attributed to natural rubber being a common target of a bacterial order commonly found in soil known as the actinomycetes (Ali Shah et al., 2013). In contrast, biodegradation of PBAT has been reported to be minimal (Tsutsumi et al., 2003; Trinh Tan et al., 2008; Ali Shah et al., 2013). It is noted, however, that the ENR particles were much coarser than the PBAT particles (Zaidi and Crosky, 2019) and this may also have affected the degradation rate.

Pantani and Sorrentino (2013) conducted biodegradation studies on PLA and reported that crystallinity is a factor that affects the biodegradation rate of PLA, with the rate being faster for amorphous samples compared to crystalline samples. The authors attributed this to crystallinity affecting the diffusion of water into the sample and presenting difficulty in access to the polymer chains for enzymatic attack by the microorganisms. Differences in time of saturation for $\mathrm{PHBV} / \mathrm{flax}$ and the toughened composites might therefore be due to differences in crystallinity between the two types of samples, as the toughened composites would have had a much lesser crystallinity as a result of addition of amorphous PBAT and ENR, as discussed in Zaidi and Crosky (2019).

\section{Surface Degradation}

One feature observed for the neat PHBV samples as well as the composites was color fading. Color fading has also been observed for PHBV/abaca (Teramoto et al., 2004), PHBV/peach palm particles (PPp) (Batista et al., 2010), and PHBV/lyocell (Shibata et al., 2004) composites. This is attributed to micro-pitting of the surface, as was observed in the SEM images shown earlier. This increases the surface roughness of the samples, and the rougher surface would subsequently scatter light to a greater extent.

With increased burial time, the level of pitting increased, initially being localized but eventually becoming more uniformly spread. The pitted regions are considered to most likely be areas 


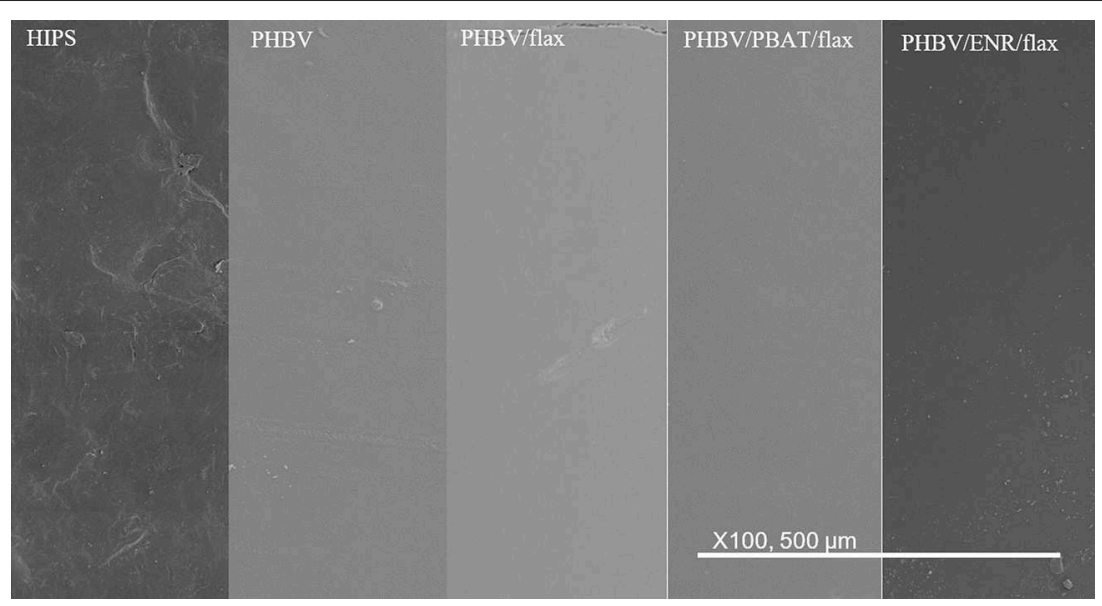

FIGURE 9 | SEM images of initial surfaces of all materials.

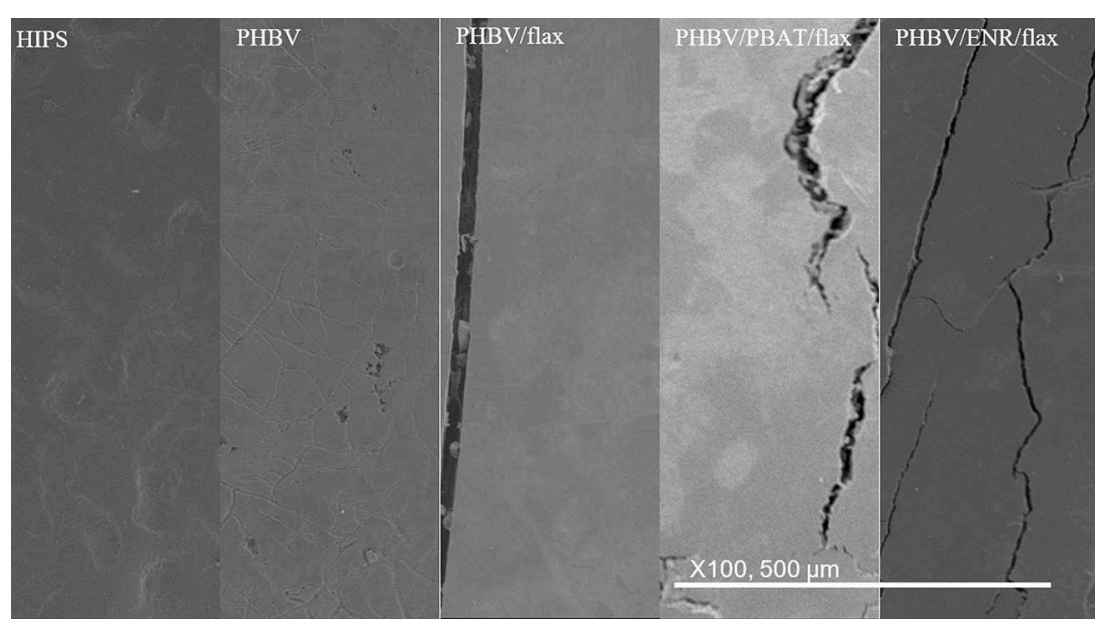

FIGURE 10 | SEM images of surfaces of all materials after 28 days.

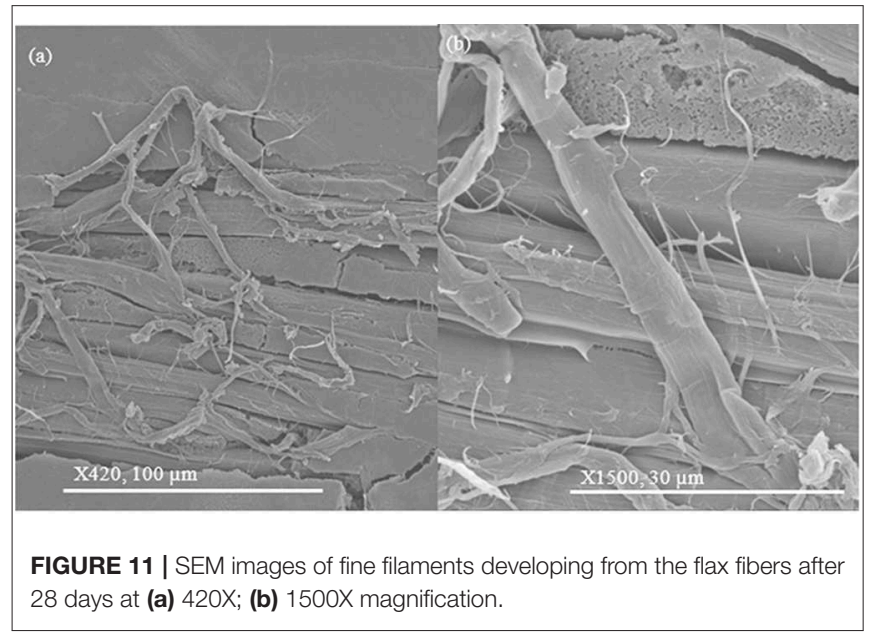

of reduced molecular weight resulting from hydrolysis of the polymer chains, which is reported to be one of the causes of the onset of degradation.

The localized pitted regions, which were seen as lightcolored regions when viewed using SEM, were more pronounced on the PHBV/ENR/flax and PHBV/PBAT/flax samples than on the PHBV/flax composite. This is attributed to lower crystallinity caused by the addition of the toughening agents (Zaidi and Crosky, 2019), since amorphous regions are known to degrade preferentially to crystalline regions (Abe and Doi, 1999; Woolnough et al., 2010).

Some workers have reported fragmentation (Teramoto et al., 2004; Batista et al., 2010) during biodegradation but this was only observed in the present study where the fibers were close to the surface, Figure 11. In these cases, it appeared that the microorganisms had exploited the fiber matrix interfaces, as proposed by Batista et al. (2010). 


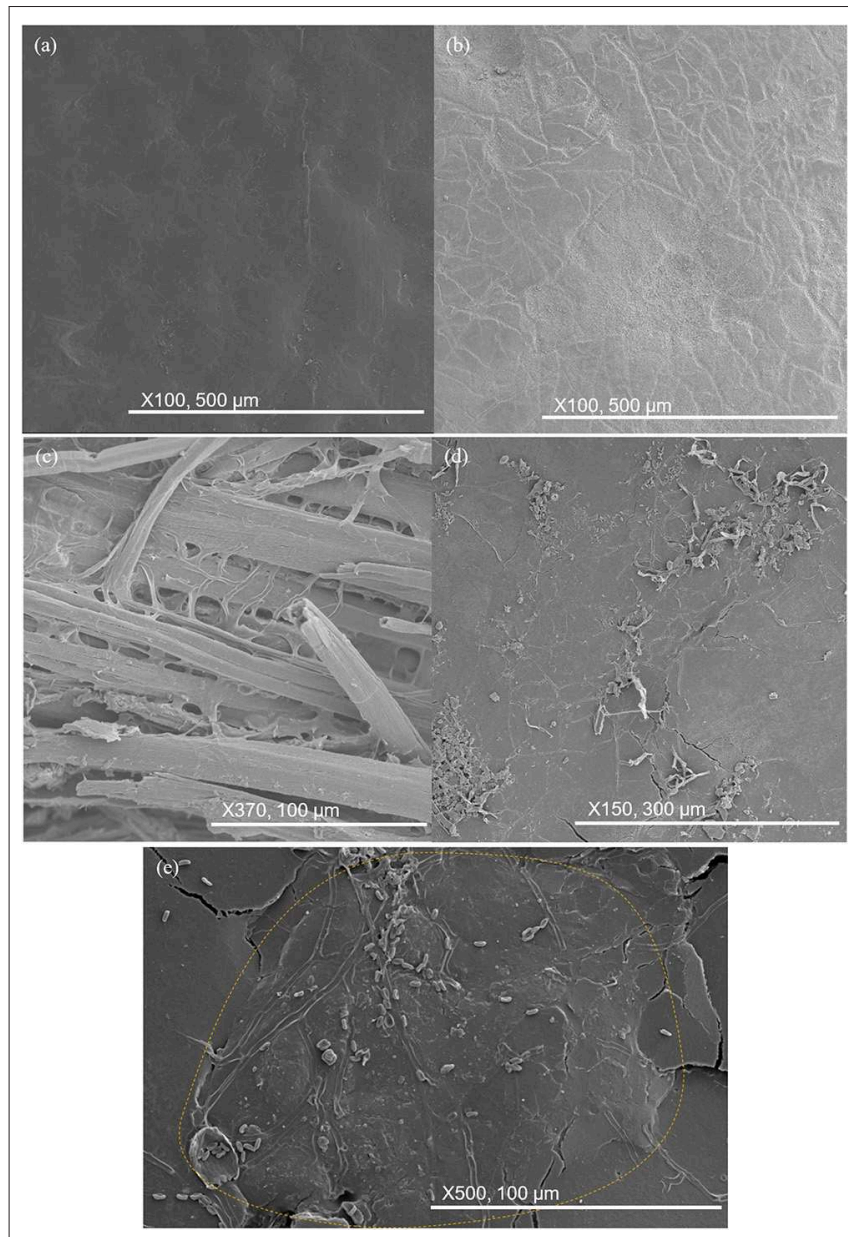

FIGURE 12 | SEM images of key changes in samples after 56 days. (a) HIPS remains unchanged; (b) craze markings on neat PHBV; (c) elementary fiber separation in composite samples; (d) filamentous structures growing on ENR particles; (e) peanut-shaped objects observed on ENR particles.

As noted above the composites developed surface cracking during soil burial but this was not observed for the neat PHBV. This difference is attributed to the higher level of PHBV crystallinity in the composites induced by nucleation at the fibers, as discussed in earlier work by Zaidi and Crosky (2019).The increased level of crystallinity would result in increased brittleness.

Submicron-sized filamentous structures were observed on flax fibers which had been exposed at the surface, Figure 11. These are likely to be fungi, which have been reported to be the primary cause of lignin-degradation (Kirk and Farrell, 1987; Avella et al., 2000). This is consistent with the observation of elementary fiber separation since lignin binds the elementary fibers together (Yan et al., 2014) and the observed separation into elementaries indicates that the lignin has been degraded.

Filamentous structures, together with peanut shaped features, were observed on the surfaces of the toughened composites. These are considered likely to be fungal hyphae, which are cylindrical cells that grow from one end and start branching
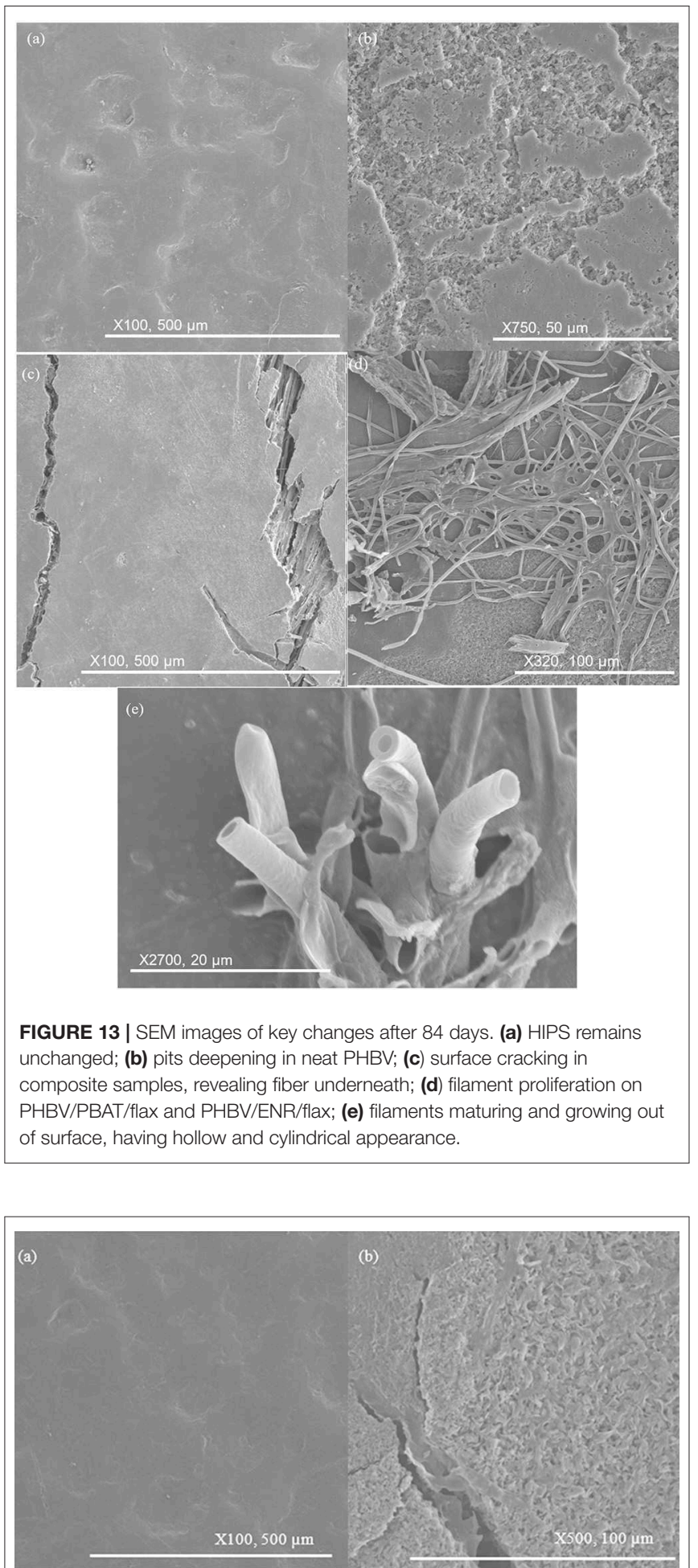

FIGURE 14 | SEM images of key changes in samples after 112 days. (a) HIPS remains unchanged; (b) pitting becomes continuous for all other samples.

to form a system of hyphae known as mycelium. The peanut shaped features are likely to be spores that initiate the hyphae structure. This is consistent with the reduction in the number of 
TABLE 1 | Mass loss data for neat PHBV reported in various studies.

\begin{tabular}{|c|c|c|c|c|}
\hline $\begin{array}{l}\text { Mass loss } \\
\%\end{array}$ & $\begin{array}{c}\text { At \# of days from } \\
\text { burial }\end{array}$ & Medium & Grade & Reference \\
\hline $10-11$ & 84 & Garden soil & Zeneca PHBV 5 mol.\% HV & Avella et al., 2000 \\
\hline $20-23$ & 168 & “ & Zeneca PHBV 5 mol.\% HV & $"$ \\
\hline 20 & 224 & Soil & Biopol unspecified HV & Barkoula et al., 2010 \\
\hline 32 & 150 & Soil & Biofan A-1000 11 mol.\% HV & Teramoto et al., 2004 \\
\hline 40 & 90 & Soil & $\begin{array}{c}\text { Biophane A-1000 (from same supplier as Teramoto } \\
\text { et al. so presumably also } 11 \mathrm{~mol} \% \mathrm{HV} \text { ) }\end{array}$ & Shibata et al., 2004 \\
\hline
\end{tabular}

peanut shaped features observed with increased development of the filamentous structures. The spores lie dormant, get dispersed through the air and, after landing on a suitable substrate, germinate under favorable conditions (Carlile, 1995). It would be expected that the spores would infiltrate into the soil, especially during periods of rain, thus allowing them to contact the buried samples.

Passos et al. (2015) observed spores and fungal hyphae on PHBV film after 1 month of degradation by a fungal solution containing the fungus Paecilomyces variotii which is an ascomycete commonly found in soil. The peanut-shaped objects in the present study resemble the spores observed by these authors. Similar structures were observed by Stieven Montagna et al. (2017) when PHBV/graphite nanosheet (GNS) nanocomposites were subject to biodegradation by the fungus Penicillium funiculosum commonly found in soil.

While filamentous structures were observed on both toughened composites, they were more prevalent and more complex on the ENR toughened samples than on the PBAT toughened samples. It is probable that some of the filamentous structures seen on the ENR toughened samples were due to an order of actinobacteria known as the actinomycetes, which are known to be primary attackers of natural rubber (Ali Shah et al., 2013). This order contains one of the largest bacterial genera, Streptomyces, which is found worldwide in soil (Faghri Zonooz and Salouti, 2011). The Streptomyces genera forms a filamentous structure which is similar to fungal mycelium. The actinomycete order are the only bacteria which form a filamentous structure (Castillo et al., 2005).

In view of the above it is considered that actinomycete bacteria and fungal mycelium were both active in the biodegradation of the ENR toughened composite samples, but only the latter were active in the PBAT toughened samples. This is considered to be the principal cause of the higher degradation rate seen for the $\mathrm{PHBV} / \mathrm{ENR} /$ flax composites.

\section{CONCLUSIONS}

Negligible biodegradation occurred in the PHBV which showed a maximum mass loss of $0.5 \%$ over the 112 days exposure period. The rate of degradation was, however, substantial for all the composites and was higher in the two toughened composites than in the untoughened PHBV/flax composite. Of the toughened composites PHBV/ENR flax showed the highest degradation rate with a mass loss of $17 \%$ being recorded after 112 days, compared with 9\% PHBV/PBAT/flax and 6\% for PHBV/flax. Filamentous structures were seen on flax fibers which had been exposed at the surface. These are considered to have been fungi which have been reported to be the primary cause of lignin-degradation, consistent with the observation of elementary fiber separation.

Other filamentous structures, together with peanut shaped features, were observed on the surfaces of the toughened composites. Filamentous structures were more prevalent and more complex on the ENR toughened samples than on the PBAT toughened samples. It is probable that some of the filamentous structures seen on the ENR toughened samples were due to an order of actinobacteria known as the actinomycetes, which are known to be primary attackers of natural rubber. The presence of these microorganisms is considered to be the primary reason for the faster degradation of the PHBV/ENR/flax composites.

These results indicate that the incorporation of ENR as a biobased toughening agent for PHBV/natural fiber composites not only enhances the toughness properties of the biocomposites but enhances their biodegradability substantially more than is achieved by addition of the commonly used toughening agent PBAT. These properties can broaden the scope of application for PHBV-based toughened and untoughened biocomposites.

\section{DATA AVAILABILITY STATEMENT}

The datasets generated for this study are available on request to the corresponding author.

\section{AUTHOR CONTRIBUTIONS}

$\mathrm{ZZ}$ and AC: conceptualization and resources. ZZ: data curation, investigation, methodology, visualization, and writing-original draft. AC: project administration. AC and DM: supervision, writing-review, and editing.

\section{ACKNOWLEDGMENTS}

The authors acknowledge Centennial Parklands, Sydney for providing land and opportunity to conduct biodegradation testing on their premises. Assistance with establishing liaison with Centennial Parklands and providing advice on 
conducting soil burial was provided by Associate Professor Bryce Kelly from the School of Biological, Earth and Environmental Sciences (BEES), UNSW. Technical support

\section{REFERENCES}

Abe, H., and Doi, Y. (1999). Structural effects on enzymatic degradabilities for poly[(R)-3-hydroxybutyric acid] and its copolymers. Int. J. Biol. Macromol. 25, 185-192. doi: 10.1016/S0141-8130(99)00033-1

Adam, J., Korneliusz, B. A., and Agnieszka, M. (2013). Dynamic mechanical thermal analysis of biocomposites based on PLA and PHBV - A comparative study to PP counterparts. J. Appl. Polym. Sci. 130, 3175-3183. doi: 10.1002/app.39562

Ali Shah, A., Hasan, F., Shah, Z., Kanwal, N., and Zeb, S. (2013). Biodegradation of natural and synthetic rubbers: a review. Int. Biodeterior. Biodegrad. 83, 145-157. doi: 10.1016/j.ibiod.2013.05.004

Alimuzzaman, S., Gong, R. H., and Akonda, M. (2014). Biodegradability of nonwoven flax fiber reinforced polylactic acid biocomposites. Polym. Compos. 35, 2094-2102. doi: $10.1002 / p c .22871$

Avella, M., Bogoeva-Gaceva, G., Buzarovska, A., Errico, M. E., Gentile, G., and Grozdanov, A. (2007). Poly(3-hydroxybutyrate-co-3-hydroxyvalerate)-based biocomposites reinforced with kenaf fibers. J. Appl. Polym. Sci. 104, 3192-3200. doi: 10.1002/app. 26057

Avella, M., La Rota, G., Martuscelli, E., Raimo, M., Sadocco, P., Elegir, G., et al. (2000). Poly(3-hydroxybutyrate-co-3-hydroxyvalerate) and wheat straw fibre composites: thermal, mechanical properties and biodegradation behaviour. $J$. Mater. Sci. 35, 829-836. doi: 10.1023/A:1004773603516

Ball, P. (2003). Material witness: e-waste not. Nat. Mater. 2:76. doi: $10.1038 /$ nmat 823

Barkoula, N. M., Garkhail, S. K., Peijs, T., Barkoula, N. M., Garkhail, S. K., and Peijs, T. (2010). Biodegradable composites based on flax/polyhydroxybutyrate and its copolymer with hydroxyvalerate. Ind. Crop. Prod. 31, 34-42. doi: 10.1016/j.indcrop.2009.08.005

Batista, K. C., Silva, D. A. K., Coelho, L. A. F., Pezzin, S. H., Pezzin, A. P. T., Batista, K. C., et al. (2010). Soil biodegradation of PHBV/peach palm particles biocomposites. J. Polym. Environ. 18, 346-354. doi: 10.1007/s10924-010-0238-4

Berthet, M. A., Angellier-Coussy, H., Chea, V., Guillard, V., Gastaldi, E., and Gontard, N. (2015). Sustainable food packaging: valorising wheat straw fibres for tuning PHBV-based composites properties. Compos. Part A Appl. Sci. Manuf. 72, 139-147. doi: 10.1016/j.compositesa.2015.02.006

Bledzki, A. K., and Jaszkiewicz, A. (2010). Mechanical performance of biocomposites based on PLA and PHBV reinforced with natural fibres - A comparative study to PP. Compos. Sci. Technol. 70, 1687-1696. doi: 10.1016/j.compscitech.2010.06.005

Bourban, C., Karamuk, E., de Fondaumiere, M. J., Ruffieux, K., Mayer, J., and Wintermantel, E. (1997). Processing and characterization of a new biodegradable composite made of a PHB/V matrix and regenerated cellulosic fibers. J. Envir. Polym. Degrad. 5, 159-166.

Buzarovska, A., Bogoeva-Gaceva, G., Grozdanov, A., Avella, M., Gentile, G., and Errico, M. (2007). Crystallization behavior of poly(hydroxybytyrate-covalerate) in model and bulk PHBV/kenaf fiber composites. J. Mater. Sci. 42, 6501-6509. doi: 10.1007/s10853-007-1527-8

Carlile, M. J. (1995). "The success of the hypha and mycelium," in The Growing Fungus, eds G. M. Gadd and N. A. R. Gow (New York, NY: Springer), 3. doi: 10.1007/978-0-585-27576-5_1

Castillo, U., Myers, S., Browne, L., Strobel, G., Hess, W. M., Hanks, J., et al. (2005). Scanning electron microscopy of some endophytic streptomycetes in snakevine - Kennedia nigricans. Scanning 27, 305-311. doi: 10.1002/sca. 4950270606

Ebadi-Dehaghani, H., Barikani, M., Borhani, S., Bolvardi, B., Khonakdar, H. A., Jafari, S. H., et al. (2016). Biodegradation and hydrolysis studies on polypropylene/polylactide/organo-clay nanocomposites. Polym. Bull. 73, 3287-3304. doi: 10.1007/s00289-016-1655-x

Faghri Zonooz, N., and Salouti, M. (2011). Extracellular biosynthesis of silver nanoparticles using cell filtrate of Streptomyces sp. ERI-3. Sci. Iranica 18, 1631-1635. doi: 10.1016/j.scient.2011.11.029 with electron microscopy was provided by Dr. Simon Hager and Dr. Katie Levick from the Electron Microscopy Unit (EMU), UNSW.

Hermida, E. B., and Mega, V. I. (2007). Transcrystallization kinetics at the poly(3hydroxybutyrate-co-3-hydroxyvalerate)/hemp fibre interface. Compos. Part A Appl. Sci. Manuf. 38, 1387-1394. doi: 10.1016/j.compositesa.2006.10.006

Javadi, A., Kramschuster, A. J., Pilla, S., Lee, J., Gong, S., and Turng, L.-S. (2010a). Processing and characterization of microcellular PHBV/PBAT blends. Polym. Eng. Sci. 50, 1440-1448. doi: 10.1002/pen.21661

Javadi, A., Srithep, Y., Lee, J., Pilla, S., Clemons, C., Gong, S., et al. (2010b). Processing and characterization of solid and microcellular PHBV/PBAT blend and its RWF/nanoclay composites. Compos. Part A Appl. Sci. Manuf. 41, 982-990. doi: 10.1016/j.compositesa.2010.04.002

Javadi, A., Srithep, Y., Pilla, S., Lee, J., Gong, S., and Turng, L.-S. (2010c). Processing and characterization of solid and microcellular PHBV/coir fiber composites. Mater. Sci. Eng. C 30, 749-757. doi: 10.1016/j.msec.2010.03.008

Keller, A. (2003). Compounding and mechanical properties of biodegradable hemp fibre composites. Compos. Sci. Technol. 63, 1307-1316. doi: 10.1016/S0266-3538(03)00102-7

Kelly, B. F. J. (1994). Electrical properties of sediments and the geophysical detection of ground water contamination (Ph.D). University of New South Wales, Australia.

Kirk, T. K., and Farrell, R. L. (1987). Enzymatic "combustion": the microbial degradation of lignin. Annu. Rev. Microbiol. 41, 465-501. doi: 10.1146/annurev.mi.41.100187.002341

Kumagai, Y., and Doi, Y. (1992). Enzymatic degradation of binary blends of microbial poly (3-hydroxybutyrate) with enzymatically active polymers. Polym. Degrad. Stab. 37, 253-256. doi: 10.1016/0141-3910(92)90167-4

La Mantia, F. P., and Morreale, M. (2011). Green composites: a brief review. Compos. Part A Appl. Sci. Manuf. 42, 579-588. doi: 10.1016/j.compositesa.2011.01.017

Luo, S., and Netravali, A. N. (1999). Interfacial and mechanical properties of environment-friendly 'green' composites made from pineapple fibers and poly(hydroxybutyrate-co-valerate) resin. J. Mat. Sci. 34, 3709-3719. doi: 10.1023/A:1004659507231

Michel, A., and Billington, S. (2014). Nonlinear constitutive model for anisotropic biobased composite materials. J. Eng. Mech. 140:04014083. doi: 10.1061/(ASCE)EM.1943-7889.0000773

Modi, S. J., Cornish, K., Koelling, K., and Vodovotz, Y. (2016). Fabrication and improved performance of poly(3-hydroxybutyrate-co-3-hydroxyvalerate) for packaging by addition of high molecular weight natural rubber. J. Appl. Polym. Sci. 133:43937. doi: 10.1002/app.43937

Mohamad, Z., Ismail, H., and Chantara Thevy, R. (2006). Characterization of epoxidized natural rubber/ethylene vinyl acetate (ENR-50/EVA) blend: effect of blend ratio. J. Appl. Polym. Sci. 99, 1504-1515. doi: 10.1002/app.22154

Nagarajan, V., Misra, M., and Mohanty, A. K. (2013a). New engineered biocomposites from poly(3-hydroxybutyrate-co-3-hydroxyvalerate) (PHBV)/poly(butylene adipate-co-terephthalate) (PBAT) blends and switchgrass: fabrication and performance evaluation. Ind. Crops Prod. 42, 461-468. doi: 10.1016/j.indcrop.2012.05.042

Nagarajan, V., Mohanty, A. K., and Misra, M. (2013b). Sustainable green composites: value addition to agricultural residues and perennial grasses. ACS Sustainable Chem. Eng. 1, 325-333. doi: 10.1021/sc300084z

Pantani, R., and Sorrentino, A. (2013). Influence of crystallinity on the biodegradation rate of injection-moulded poly(lactic acid) samples in controlled composting conditions. Polym. Degrad. Stab. 98, 1089-1096. doi: 10.1016/j.polymdegradstab.2013.01.005

Passos, T. M., Marconato, J. C., and Franchetti, S. M. M. (2015). Biodegradation of films of low density polyethylene (LDPE), poly(hydroxibutyrate-co-valerate) (PHBV), and LDPE/PHBV (70/30) blend with Paecilomyces variotii. Polimeros 25, 29-34. doi: 10.1590/0104-1428.1432

Persico, P., Acierno, D., Carfagna, C., and Cimino, F. (2011). Mechanical and thermal behaviour of ecofriendly composites reinforced by Kenaf and Caroà fibers. Int. J. Polym. Sci. 2011, 1-7. doi: 10.1155/2011/841812 
Rahman, M. A., Sartore, L., Bignotti, F., and Di Landro, L. (2013). Autonomic selfhealing in epoxidized natural rubber. ACS Appl. Mater. Interfaces 5, 1494-1502. doi: 10.1021/am303015e

Rossa, L. V., Scienza, L. C., and Zattera, A. J. (2013). Effect of curaua fiber content on the properties of poly(hydroxybutyrate-co-valerate) composites. Polym. Compos. 34, 450-456. doi: 10.1002/pc.22432

Russo, P., Carfagna, C., Cimino, F., Acierno, D., and Persico, P. (2013). Biodegradable composites reinforced with Kenaf fibers: thermal, mechanical, and morphological issues. Adv. Polym. Technol. 32, E313-E322. doi: $10.1002 / \mathrm{adv} .21282$

Savadekar, N. R., Kadam, P. G., and Mhaske, S. T. (2015). Studies on the effect of nano-alumina on the performance properties of poly(butylene adipate-coterephthalate) composite films. J. Thermoplast. Compos. Mater. 28, 1522-1536. doi: $10.1177 / 0892705713513292$

Shibata, M., Oyamada, S., Kobayashi, S., Yaginuma, D., Shibata, M., Oyamada, S., et al. (2004). Mechanical composites and biodegragability of green composites based on biodegradable polyesters and lyocell fabric. J. Appl. Polym. Sci. 92, 3857-3863. doi: 10.1002/app.20405

Shibata, M., Takachiyo, K.-I., Ozawa, K., Yosomiya, R., and Takeishi, H. (2002). Biodegradable polyester composites reinforced with short abaca fiber. J. Appl. Polym. Sci. 85, 129-138. doi: 10.1002/app.10665

Srithep, Y., Ellingham, T., Peng, J., Sabo, R., Clemons, C., Turng, L.S., et al. (2013). Melt compounding of poly (3-hydroxybutyrate-co-3hydroxyvalerate)/nanofibrillated cellulose nanocomposites. Polym. Deg. Stabil. 98, 1439-1449. doi: 10.1016/j.polymdegradstab.2013.05.006

Srubar, W. V., Pilla, S., Wright, Z. C., Ryan, C. A., Greene, J. P., Frank, C. W., et al. (2012). Mechanisms and impact of fiber-matrix compatibilization techniques on the material characterization of $\mathrm{PHBV} / \mathrm{oak}$ wood flour engineered biobased composites. Compos. Sci. Technol. 72, 708-715. doi: 10.1016/j.compscitech.2012.01.021

Stieven Montagna, L., Amaral Montanheiro, T. L. d., Chiodi Borges, A., Yumi Koga-Ito, C., Paula Lemes, A., Cerqueira Rezende, M. (2017). Biodegradation of PHBV/GNS nanocomposites by Penicillium funiculosum. J. Appl. Polym. Sci. 13(4), n/a-n/a. doi: 10.1002/app.44234

Teramoto, N., Urata, K., Ozawa, K., and Shibata, M. (2004). Biodegradation of aliphatic polyester composites reinforced by abaca fiber. Polym. Degrad. Stab. 86, 401-409. doi: 10.1016/j.polymdegradstab.2004.04.026

Trinh Tan, F., Cooper, D. G., Maric, M., and Nicell, J. A. (2008). Biodegradation of a synthetic co-polyester by aerobic mesophilic microorganisms. Polym.
Degrad. Stab. 93, 1479-1485. doi: 10.1016/j.polymdegradstab.2008. 05.005

Tsutsumi, C., Hayase, N., Nakagawa, K., Tanaka, S., and Miyahara, Y. (2003). The enzymatic degradation of commercial biodegradable polymers by some lipases and chemical degradation of them. Macromol. Symp. 197, 431-442. doi: 10.1002/masy.200350737

Vanleeuw, B., Carvelli, V., Barburski, M., Lomov, S. V., and van Vuure, A. W. (2015). Quasi-unidirectional flax composite reinforcement: deformability and complex shape forming. Compos. Sci. Technol. 110, 76-86. doi: 10.1016/j.compscitech.2015.01.024

Woolnough, C. A., Yee, L. H., Charlton, T., and Foster, L. J. R. (2010). Environmental degradation and biofouling of 'green' plastics including short and medium chain length polyhydroxyalkanoates. Polym. Int. 59, 658-667. doi: $10.1002 /$ pi.2746

Yan, L., Chouw, N., and Jayaraman, K. (2014). Flax fibre and its composites - A review. Compos. Part B Eng. 56, 296-317. doi: 10.1016/j.compositesb.2013.08.014

Zaidi, Z., and Crosky, A. (2019). Unidirectional rubber-toughened green composites based on PHBV. Sustainability 11:2411. doi: 10.3390/su11082411

Zhang, K., Misra, M., and Mohanty, A. K. (2014a). Toughened sustainable green composites from poly(3-hydroxybutyrate-co-3-hydroxyvalerate) based ternary blends and Miscanthus biofiber. ACS Sustainable Chem. Eng. 2, 2345-2354. doi: $10.1021 /$ sc500353v

Zhang, K., Nagarajan, V., Zarrinbakhsh, N., Mohanty, A. K., and Misra, M. (2014b). Co-injection molded new green composites from biodegradable polyesters and miscanthus fibers. Macromol. Mater. Eng. 299, 436-446. doi: 10.1002/mame.201300189

Conflict of Interest: The authors declare that the research was conducted in the absence of any commercial or financial relationships that could be construed as a potential conflict of interest.

Copyright (C) 2019 Zaidi, Mawad and Crosky. This is an open-access article distributed under the terms of the Creative Commons Attribution License (CC BY). The use, distribution or reproduction in other forums is permitted, provided the original author(s) and the copyright owner(s) are credited and that the original publication in this journal is cited, in accordance with accepted academic practice. No use, distribution or reproduction is permitted which does not comply with these terms. 